\title{
Editorials
}

\section{An Editor's farewell}

As this is the last issue of the Postgraduate Medical fournal with which I shall be involved as Editor, I would like to congratulate and welcome my successor, Dr John Mayberry, and to wish him every good fortune in the post. My own interest in medical publications will continue, however, as Director of Publications at the Royal College of Physicians in London.

Over the last four years the Postgraduate Medical fournal has developed into a useful vehicle to help trainees to prepare for postgraduate examinations (such as the MRCP (UK)), and to keep specialty registrars and Consultants abreast of developments in other specialties. Its success has been demonstrated by the satisfying increase in subscriptions during this period, from both libraries and private individuals.

That success is thanks to the hard work of the numerous referees who have passed opinions on the hundreds of manuscripts sent to the journal each year, and to the support and suggestions from present and past members of the Editorial Board. In addition, I would like to thank the large number of eminent colleagues who have kindly written the review articles which now form the backbone of each issue of the journal.

On a personal note I would like to thank both Jean Coops and, more recently, Elizabeth Young, for all their hard work and support as Editorial Assistants. I am also grateful to Sue Peter, Technical Editor, for ensuring that each issue of the journal is presented in the best possible way, and to Alex Williamson at BMJ Publications who has helped enormously to raise the profile of the Postgraduate Medical fournal over the last four years. Finally I would like to thank the Senior Officers of the Fellowship of Postgraduate Medicine, the owners of the journal, who kindly asked me to take this role, and I wish them well in the future.

Being the Editor of the Postgraduate Medical fournal has without a doubt been time consuming and very hard work. I have, however, thoroughly enjoyed my tenure, and feel that I have earnt enough Continuing Medical Education credits to last me into the next millennium! Thank you again. 